\title{
Logistics and supply chain management of food industry during COVID-19: disruptions and a recovery plan
}

\author{
Abhijit Barman $^{1} \cdot$ Rubi Das $^{1} \cdot$ Pijus Kanti De ${ }^{1}$ \\ Accepted: 11 October 2021 / Published online: 20 October 2021 \\ (c) The Author(s), under exclusive licence to Springer Science+Business Media, LLC, part of Springer Nature 2021
}

\begin{abstract}
An ongoing worldwide pandemic, known as Covid infection 2019 (COVID-19), influences the food supply chains significantly. In the pandemic situation, the movements of the people are restricted due to strict lock-down, and retail shops are closed. The supply of products to the customer is a challenging situation for the food supplier. These disruptions impact the food supply chain system suddenly, and the process can collapse without necessary and immediate actions. In this paper, a direct delivery channel has been used as a recovery strategy to minimize the effects of disruptions in the pandemic situation. In the recovery plan, the manufacturer appoints vendors and delivers the products directly to the customers by introducing multi-delivery channels. We optimize the recovery plan under the profit maximization criteria from the recovery window. Some numerical examples have been illustrated to justify that the developed recovery model can resist the reduction of demand and improve the profit of the system. Also, managerial insights are discussed which help the decision-makers to make an accurate and prompt decision of designing a recovery strategy during COVID-19.
\end{abstract}

Keywords COVID-19 $\cdot$ Pandemic $\cdot$ Supply chain $\cdot$ Inventory $\cdot$ Price-sensitive demand $\cdot$ Recovery model

\section{Introduction}

Manufacturing firms have been confronting the uncommon outbreak of coronavirus disease (COVID-19) since December 2019. In India, first phase of this disease is very effective from March to July 2020. All country is under lockdown and manufacturing firm is severe and medium-to-long-term effects are anticipated to be higher than that of any different past significant outbreak, for example, 2003 SARS and 2009 H1N1. Besides, the extreme spread of the infection into Europe and the USA has restricted the movement of the items and materials around the world. This disease has come about not just in the worldwide misfortune for human deaths yet in addition touches the economic sectors and exercises, including manufacturing, inventory network strategic, and

Abhijit Barman

abhijitmath93@gmail.com

Rubi Das

rubidas1118@gmail.com

Pijus Kanti De

pijusde@gmail.com

1 Department of Mathematics, National Institute of Technology Silchar, Silchar, Assam 788010, India so forth. Accordingly, it has become difficult for a supply chain to continue the activities involved. Some operations of the chain have stopped and supply chain disruptions occur. The lockdown was forced in a few nations to control the fatalities and loss of physical well-being, and around 2.6 billion people have been home isolated in India, South Africa, the USA, alongside other European nations in March and April of the year 2020. Due to lockdown, customers do not want to go to the market and some retail shops are temporarily closed eventually resulted in supply chain disruptions. It acquires a sudden change in demand from the customer side and a significant rise in the price of the product because of restrictions associated with supply chain disruptions as well as panic buying. Price is often considered as a decision variable in most of the inventory literature which needs to be optimized and most of the inventory model, demand is considered as price-sensitive (Barman et al. 2020; Maihami and Kamalabadi 2012). Hence pricing strategy is necessary to increase the ability of organizations.

Each industry on the planet hopes to perceive how the COVID-19 episode will influence the working, and the food industry is no different from other organizations. However, the distinction of the food industry from other industries is to deliver items that are fundamental needs 
for daily life. In addition, the food business is a significant area in regard to economy. During the current COVID-19 pandemic, some difficult decisions must be made, including temporarily shut down of the different organizations. Pandemic may prompt $113 \mathrm{~B}$ misfortune in aeronautics and $80 \mathrm{~B}$ in the travel industry area (IATA 2020; UNTWO 2020). Some food organizations face different difficulties because of a drop in pay, while others are endeavoring to satisfy the developing need of retailers (Sebastian 2020). A significant concern shared by all food organizations is saving the employee health and keeping up with accessibility of laborers because of sickness or declining to work due to Covid fear (de Sousa Jabbour et al. 2020). Regardless of the enormous size of the pandemic, there is no report that COVID-19 has been communicated through food utilization to date. Consequently, as expressed by the European Food Safety Authority, there is no proof that food poses a risk to public health in relation to COVID-19. Moreover, after the most recent contamination has been seen in the Xinfandi market because of salmon preparation, it concluded that there is generally a low risk of food sources conveying the infection although the apparent risk is high (Pressman et al. 2020). To guarantee the continuity of the food stream for each stage can be assembled in food representative's medical problems. Consequently, the inventory network is fundamentally influenced when laborers are missing from work because of infection or travel limitations of the neighborhood because of lockdown. It additionally weakens creation capacities for other people, yet in addition their own food handling, in situations where the infection straightforwardly influences their health or development (FAO 2020b).

Multi-channel client, the executives, is the utilization of more than one channel or medium to oversee clients in a reliable and composed way across all channels or media utilized. Separate web channels frequently had their destinations, the board, staff, and frameworks, typically experienced raising costs, given a client experience which was altogether different from that of different channels, and in some cases made brand harm and expanded client beat. This paper aims to help local manufacturing companies, especially the food industry, by determining their strategies and tactics in this area, offering multi-channel in lockdown situations.

The practical profit/loss functions might be more complex but our proposed model does not give a total formula to multi-channel management.

The remainder of the paper is structured as follows: Section 2 carried out the literature review, Sect. 3 suggest some disruptions and a recovery plan during the pandemic of food industry. The mathematical model formulation of the problem and the theoretical solution of the model is presented in Sect. 4. The findings from the numerical and discussion are presented in Sect. 5. Also Sect. 6 gives the managerial insights of the model. Finally, the conclusion and future research direction are presented in Sect. 7.

\section{Literature review}

Based on the severity of disruptions in the supply chain, recovery plans for the supply chain are needed. The recovery plan for more severe and less severe supply chain are different (Pavlov et al. 2019a). Food varieties that are not become locally yet required for preparing, were not accessible because of the limitations and limit usage of food producing plants to react demand was additionally contrarily influenced (Arianina and Morris 2020; Ndemezo et al. 2018). Dairy Farmers in America Cooperative appraised 14 million liters of milk are being unloaded each day because of discontinue on production network. In England, seat of dairy farmers revealed that roughly 5 million liters of milk are in danger in multi week. At the point when the restrictive arrangements were applied, neighborhood merchants could not discover purchasers and brought about abundance supply and waste alongside economic losses. The greatest issues in the food inventory network are acquiring crude materials from providers and guaranteeing the progression of food stream from producers to end clients (Alonso et al. 2007). Close-down of food sectors made the gradually expanding influence in food inventory network. More prominent purchaser demand brought about void racks and a reduction in supply caused an expansion in the price.

The difficulties have been driven by movement restrictions (public or worldwide line terminations) is not the main explanation yet, in addition, the changes of demand from customers are crucial. Due to the limitations, buyers cannot go to cafes and set up their meals at home. Likewise, shoppers would prefer not to go to business sectors and stores because of getting the COVID-19 at the stores. Buyer has preferred home delivery choices because of maintaining social separation and shutting of retail shops. (Shahidi 2020). Despite government consolations, a portion of the stores limited the measure of each produce that a client needs to purchase and began free delivery service on orders to prevent panic buying. Due to begin of home delivery service, supermarkets, shopping mall etc. are abled to determine the number of individuals in at any given time which stop the overcrowding. Stores additionally changed uncommon shopping hours for weak clients. There are many reports that suppliers of various products were forced to destroy their products due to restrictions. For example, Dairy farmers have dumped million liter of milk every day due to restrictions, tea plants were damaged due to logistical challenges in India. In a pandemic situation like COVID-19, manufacturing firms are needed to make an extraordinary and robust plan to survive in supply chain disruption. Many 
pandemics affected the manufacturing firms in past decades which has a significant impact on supply chain operations and productivity of commercial products but most of the research of epidemic outbreak focused on humanitarian logistics. Most of the literature on the epidemic outbreak considers humanitarian logistics to establish various strategies and models to (1) find the optimum level of inventory for supplies and commodities. (2) decide the replenishment strategy. (3) selection of optimal mode of transportation etc. Otherwise, research on business items considering pandemic is rare.

Indeed, even the literature that inspect business items, generally explore the effect of pandemic instead of planning a recovery strategy and model for various items to react to the pandemic for fast recovery. Utilizing a simulation study, prediction of effect of COVID, and finding conclude that opening of the facilities at different hubs may get one of the most influential factors that choose the effect on the operations (Ivanov and Dolgui 2020; Singh et al. 2020). An explicit focus on agriculture and food supply chain is reviewed and summarize the direction to control and reduce the impact of the epidemic outbreak (Aday and Aday 2020). A value-oriented, proactive, long-term approach to supply chain management increase firms' strength to adapt to an exceptionally unstable and extreme functions (Trautrims et al. 2020). The detection tools are developed to explore the effect of COVID-19 pandemic in the food supply chain and food industry (Rizou et al. 2020). In the uncertain market demand, illustration of optimal inventory is a necessary part to an industry to maintain the supply chain profit. Different researchers (Barman et al. 2021a, b; Das et al. 2021a, b) have developed different inventory structure in an uncertain market demand.

Hosseini et al. (2019) introduced another definition for supply chain resilience in view of the flexibility limit of supply chain and reviewed both quantitative and qualitative drivers of supply chain resilience. Hosseini and Barker (2016) presented a novel Bayesian organization model for assessing furthermore, choosing the best provider across measures falling into essential (or customary), green, and flexibility classes. Hosseini et al. (2016) initially classified four areas for meanings of flexibility: social, organizational, financial, and engineering to give a scientific categorization and review of ways to deal with measure system resilience. Hosseini and Ivanov (2020) reviewed the plans to present Bayesian networks into supply chain hazard and resilience research. Hosseini et al. (2020) speculated the open-framework setting of supply chain resilience and fosters a strategy for its estimation.

Galaitsi et al. (2021) presented a reasonable outlining to relate the ideas for the management purposes. Golan et al. 2020 surveyed inventory network resilience writing that spotlights resilience modeling and evaluation and interfaces the inventory network to different organizations, including transportation and order and control. Linkov et al. (2020) gives a viewpoint on resilience as both a development and supplement of hazard investigation and analyzed uses of the two ideas inside current value chain literature and within supply chain literature. Trump and Linkov (2020) assembles early thoughts and results from utilization of resilience and versatility investigation to the COVID-19 pandemic.

In recent years, numerous studies have been conducted on the production recovery model for managing disruptions by considering a few recovery strategies. For making the supply chain more flexible, appropriate recovery strategies are needed. Organizations which are failed to execute suitable recovery strategy failed soon after the supply chain interruptions. In the production recovery model, disturbances in all significant parts of the supply chain, for example, downstream distribution, inward production side, the upstream supply side, management of demand have been considered. Most attention has been received on such type of supply chain in which disruptions occur due to financial and political instability, natural disasters, machine failure, etc. by (Paul and Chowdhury 2020; Safaeian et al. 2019). Various recovery models were designed considering demand disruptions (Ali and Nakade 2017), transportation and scheduling disruptions (Paul et al. 2019), dual disruptions such as supply and transportation disruptions (Hishamuddin et al. 2015), risk mitigation model to manage COVID-19 pandemic (Shahed et al. 2021).

In the above studies, many researchers were proposed various recovery strategies for disruptions such as buffer stock (Darom et al. 2018), backorder (Hishamuddin et al. 2015), redesign and reconstructing of supply chain structure (Ivanov et al. 2016), backup suppliers and elective sourcing (Pavlov et al. 2019b). Also, a combination of more than one of these strategies was proposed in (Lücker et al. 2019). Depending upon the specific situation and condition one strategy might be favored over others. Appropriate and careful selection of strategies by considering different factors, for example, duration, severity, and area affected is essential.

While existing literature made useful contributions in the study of an organization or supply chain to manage less severe to more severe disruptions, none of these investigations considered exceptional outbreaks such as pandemic or epidemic disruptions as explained in the above paragraphs. Subsequently, the above-mentioned production recovery models are not readily suitable to deal with a pandemic interruption like COVID-19. Some of the recovery strategies considered in this study are not applicable to pandemic situations like where retail shops are closed and also customers are not able to go to the market. Most of the literature considered recovery strategies such as back-order, buffer stock. These strategies are not useful to recover from a pandemic for the suspended facility of product delivery to 
customer. Besides, during a pandemic situation manufacturing firms need to deliver the product directly to the customer by appointing vendors to fulfill the customer demand quickly. This strategy was not considered in any of the previous mathematical modeling. By considering the strategy, this study demonstrates how a direct delivery channel strategy can be used during an epidemic outbreak to formulate a recovery plan in the closure of a retail shop.

The motivation of this study is operated by considering the insufficiency of studies on production recovering modeling in pandemic situations.

1. Firstly, by what method would manufacturing firms be able to make their optimal decisions on their production recovery to address supply chain disruptions originated by a severe pandemic like COVID-19?

2. What are the managerial insights of the proposed recovery model?

Responding to the above inquiries, this investigation builds up a mathematical model considering supply chain disruptions and optimizes the revised delivery plan in the recovery window. A numerical example is provided to display how the model can optimize the recovery plan. The main contribution of this study is, firstly, building up a mathematical model for supply chain recovery considering the effects of a pandemic, for example, COVID-19. Secondly, consideration of dual disruptions such as the suspended facility of retail shop due to lock-down and restriction on movement of customer. Thirdly, a direct delivery channel of the manufacturer to the customer is established.

\section{Disruptions in food supply chain \& recovery plan}

COVID-19 is influencing the food and Agri supply chain in two huge perspectives: food supply and food demand cited by the Food and Agriculture Organization (FAO 2020a). COVID-19 has an impact on the entire cycle from the field to the client, as demonstrated in the food inventory network, which might be one of the economy's key regions. Because of recent issues with the food supply chain, there is a lot of concern about food production, preparation, movement, and solicitation right now. Workers' advancement limits, limited food trade approaches, and monetary growth in the food creation organization were all overcome by COVID pandemic. Disturbances in meat handling, for example, can "disconnect" the fresh food market, resulting in parallel surpluses for producers and shortages for consumers. Demand has reduced for a few select items, indicating an ephemeral excess supply (for example, milk for cheddar, potatoes for French fries). During the early stages of the epidemic, buyers may have noticed empty racks in stores, as food supply was disrupted by the sudden demand overflow.

\subsection{Lockdown effect}

Because of lockdown, the inventory network is on a very basic level impacted when workers missing from work due to sickness or limitations in the movement of neighborhood and migrant workers. It diminishes the organization's production capacity and an adverse consequence on employees own food safety. Purchaser chooses home delivery due to social distance and closing of shops. Buyers have focused in on the things with long time span of usability, for instance, dried or canned sustenance, milk, pasta, or milk substitutes because of convenience, and ordinary cooking at home.

\subsection{Food supply}

Preservation of logistic coherence is a fundamental component in the food business at the hour of worldwide calamity. The best issue in the food store network is getting assets from providers and ensuring the movement of food development from makers to purchasers.

\subsection{Food demand}

In view of monetary misfortune and assigning their resources focusing on financial inspiration and public assistance programs, governments of the different nations are confronting financial pressure. It is possible that deficient financing may reduce the demand for Agri items and efficiency.

\subsection{Food security}

Food security surmises that everyone has a limitless way to deal with food that grants them to satisfy their basic prerequisite. There are a couple of purposes behind impacting which produce food dealing with administrations expected hotbeds for the pandemic.

\subsection{Worker unavailability in industry}

Because of lockdown, the supply chain network is in a general sense impacted when workers are missing from work on account of disorder or limitations in the movement of people. Shortage of workers in view of COVID-19 crisis caused extreme breaks in specific regions like agribusiness, planting, gathering, and getting ready of harvests, which are large laborers concentrated. Worries about COVID infections are broad, and it covers both financial and medical conditions. We see that the clients' food utilization conduct has changed due to the fact that clients are willing to purchase good food without surpassing the normal spending budget. 


\subsection{Recovery plan}

Hygiene ought to be kept up with by the food administrators due to the fact that the survival time of the COVID infection on the outer layer of the steel, plastic, and so forth is extremely long. Also, the food administrators ought to be intended to prevent disease of food by the infection. Wellbeing measures to ensure the constant progression of food store network at each stage can be partitioned into self-hygiene, medical problems of the specialists, utilization of self-hardware like gloves, covers, caps, keep social separation, surface, and workspace are disinfected, securely conveyance of food, and so on.

\section{Mathematical formulation and description}

In this paper, we consider a manufacturing firm that produces a single product and stores the product. In the supply chain system before pandemic, we assume that the demand from the customer side is $D(=a-b p)$; here $a$ is market potential and $b>0$ is the price elasticity parameter. Generally, the manufacturer sells the product through a retail channel to fulfill customer demand. During COVID-19, the retail shops are closed, and customers also unable to go to market due to strict lock-down. Due to having these interruptions, it is vital to plan the proper recovery strategies and optimize the decisions accordingly. To build up the recovery model, we consider the accompanying strategy to minimize the effect of disruptions.

\subsection{Establishing multiple delivery channel}

During a pandemic, customer can place their order by online mode and the manufacturing firm has to supply the products to the customer by some direct multiple delivery channels through the vendor. We assume two delivery channels that supply the products from the manufacturing firm to the customer. The manufacturing firm has sold the products either by delivery channel 1 or delivery channel 2 . So, the demand at the delivery channel 1 is $D_{1}=a_{1}-b_{1} p_{1}$ and the demand at the delivery channel 2 is $D_{2}=a_{2}-b_{2} p_{2} ; a_{1}, a_{2}$ are market potential and $b_{1}, b_{2}>0$ are price elasticity parameters. We assume that the market potential at before pandemic will not be reduced in the recovery supply chain system due to the delivery facility at the customer's location, i.e., $a=a_{1}+a_{2}$. Although the different selling prices through retail or delivery channel, we assume that there has no demand reduction during the pandemic, i.e., $D \simeq D_{1}+D_{2}$. There are also some additional costs for both the delivery channels and they sanitize the products to prevent infection.

In the recovery model, the main objective is to resist the reduction of customer demand in this critical lock-down
Table 1 .

\begin{tabular}{ll}
\hline$M$ & Manufacturing cost per unit \\
$h$ & Holding cost per unit \\
$P$ & Production rate \\
$f$ & Sanitizing cost per product \\
$O$ & Ordering cost \\
$p$ & Selling price through retail channel \\
$p_{1}$ & Selling price through delivery channel 1 \\
$p_{2}$ & Selling price through delivery channel 2 \\
$v_{1}$ & Delivery cost for channel 1 \\
$v_{2}$ & Delivery cost for channel 2 \\
$D$ & Demand through retail channel \\
$D_{1}$ & Demand through delivery channel 1 \\
$D_{2}$ & Demand through delivery channel 2 \\
$T P$ & Total profit \\
\hline
\end{tabular}

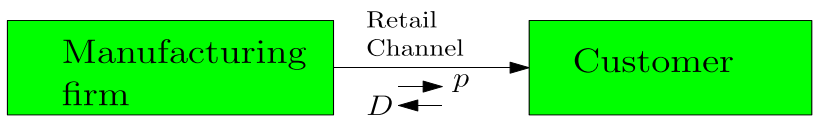

Fig. 1 Structure of before pandemic situation of supply chain

situation and to maximize the overall profit in the recovery window. In the following subsections, we discuss the mathematical models for the before pandemic supply chain system and after pandemic supply chain system with recovery plan.

The following notations are used to establish the model (Table 1).

\subsection{Profit function analysis before pandemic situation}

The manufacturing firm makes the product with a manufacturing $\operatorname{cost} M$ and sells the product at a selling price $p$ to fulfill customer demand $D$ shown in Fig. 1. The manufacturer invests a holding cost of $h$ to store the product at his warehouse. We evaluate the total profit for before pandemic supply chain and various costs related to inventory.

There are different inventory costs of the manufacturer are as follows:

1. Manufacturing cost $=M * D$

2. Ordering cost $=O$

3. Holding cost $=h \frac{D^{2}}{2 P}$

4. Sales Revenue $=p * D$

Assimilating all these costs the total profit of the manufacturing firm is 
$T P=(p-M)(a-b p)-O-h \frac{(a-b p)^{2}}{2 P}$.

To maximize the total profit

$\frac{\partial T P}{\partial p}=a-2 b p+b M+\frac{h b}{P}(a-b p)=0 \quad$.

After simplifying, the selling price in the before pandemic supply chain system is determined as follows

$p=\frac{\left(a+b M+\frac{h a b}{P}\right)}{\left(2 b+\frac{h b^{2}}{P}\right)}$.

The solution $p$ is optimal as $\frac{\partial^{2} T P}{\partial p^{2}}=-2 b-\frac{h b^{2}}{P}<0$ and denoted by $p^{*}$.

\subsection{Profit function analysis during pandemic with a recovery plan}

In the recovery plan, we have introduced two direct delivery channels that deliver the product from manufacturer to customer with different selling price $p_{1}$ (for delivery channel 1) and $p_{2}$ (for delivery channel 2 ). We assume that the demand faced by the manufacturing firm in both the delivery channels are

$D_{1}=a_{1}-b_{1} p_{1}$,

$D_{2}=a_{2}-b_{2} p_{2}$.

The recovery model is shown in Fig. 2. We have added different parameters correlated with COVID-19 such as sanitizing cost, delivery cost. These COVID-19 related parameters make the supply chain recovery model extraordinary. In the recovery model, we have established mathematical equations for different costs such as manufacturing cost, holding cost.

Now, different inventory costs of the manufacturer in the recovery model are calculated as follows

1. Manufacturing cost is determined by multiplying per unit manufacturing cost by total demand quantity for both the channels. Manufacturing cost $=M *\left(D_{1}+D_{2}\right)$
2. Ordering cost $=O$

3. Holding cost is evaluated by multiplying per unit holding cost, average inventory quantity of both the channels, and time required to keep the inventory. Holding cost $=$ $h \frac{\left(D_{1}+D_{2}\right)^{2}}{2 P}$

4. To prevent infection, the manufacturer sanitizes the product and pay an extra cost of sanitizing. This cost is calculated by multiplying by per unit sanitizing cost with inventory of both the channels. Sanitizing cost $=$ $f *\left(D_{1}+D_{2}\right)$

5. Multiplying per unit delivery cost of delivery channel 1 with demand at this channel gives delivery cost of channel 1 , i.e., $v_{1} D_{1}$. Similarly delivery cost at channel 2 , i.e., $v_{2} D_{2}$. The total delivery cost of the supply chain system during a pandemic is the sum of the delivery cost at both the channels. Delivery cost $=v_{1} D_{1}+v_{2} D_{2}$

6. Sales revenue at channel 1 , i.e., $p_{1} D_{1}$ is obtained by multiplying selling price $\left(p_{1}\right)$ at channel 1 with demand $D_{1}$. $p_{2} D_{2}$ is the sales revenue for delivery channel 2 . Sum of sales revenue for both the delivery channels gives total sales revenue for recovery supply chain system. Sales Revenue $=p_{1} D_{1}+p_{2} D_{2}$

The objective function is the maximization of profit in the recovery window. Assembling all the costs the total profit of the supply chain is calculated as

$$
\begin{aligned}
T P= & \left(p_{1}-v_{1}-M-f\right)\left(a_{1}-b_{1} p_{1}\right) \\
& +\left(p_{2}-v_{2}-M-f\right)\left(a_{2}-b_{2} p_{2}\right)-O \\
& -\frac{h}{2 P}\left[\left(a_{1}+a_{2}\right)-\left(b_{1} p_{1}+b_{2} p_{2}\right)\right]^{2}
\end{aligned} .
$$

Differentiating $T P$ partially with respect to $p_{1}$ and $p_{2}$, we get

$$
\begin{aligned}
\frac{\partial T P}{\partial p_{1}}= & \left(a_{1}-b_{1} p_{1}\right)-b_{1}\left(p_{1}-v_{1}-M-f\right) \\
& +\frac{h b_{1}}{P}\left[\left(a_{1}+a_{2}\right)-\left(b_{1} p_{1}+b+{ }_{2} p_{2}\right)\right]
\end{aligned}
$$

Fig. 2 Structure of recovery supply chain

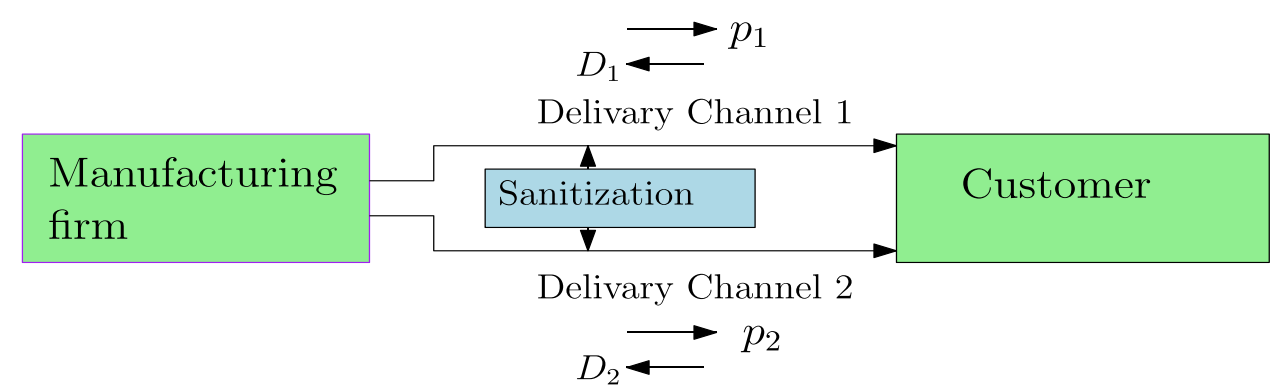




$$
\begin{gathered}
\frac{\partial T P}{\partial p_{2}}=\left(a_{2}-b_{2} p_{2}\right)-b_{2}\left(p_{2}-v_{2}-M-f\right)+ \\
\frac{h b_{2}}{P}\left[\left(a_{1}+a_{2}\right)-\left(b_{1} p_{1}+b+{ }_{2} p_{2}\right)\right]
\end{gathered} .
$$

For maximum value of $T P$, Eq. (7) and Eq. (8) are individually zero. Then from $\frac{\partial T P}{\partial p_{1}}=0$ and $\frac{\partial T P}{\partial p_{2}}=0$ we get the solutions $p_{1}$ and $p_{2}$. The closed form of the solutions $p_{1}$ and $p_{2}$ is not find analytically. We have evaluated the solutions $\left(p_{1}, p_{2}\right)$ numerically in section 5 .

To show the optimality of the solutions $p_{1}$ and $p_{2}$, we have

$\frac{\partial^{2} T P}{\partial p_{1}^{2}}=-2 b_{1}-\frac{h b_{1}^{2}}{P}<0$,

$\frac{\partial^{2} T P}{\partial p_{2}^{2}}=-2 b_{2}-\frac{h b_{2}^{2}}{P}<0$,

$\frac{\partial^{2} T P}{\partial p_{1} \partial p_{2}}=-\frac{h b_{1} b_{2}}{P}$

Here,

$$
\left(\frac{\partial^{2} T P}{\partial p_{1}^{2}}\right)\left(\frac{\partial^{2} T P}{\partial p_{2}^{2}}\right)-\left(\frac{\partial^{2} T P}{\partial p_{1} \partial p_{2}}\right)^{2}=4 b_{1} b_{2}+\frac{2 h b_{1} b_{2}}{P}\left(b_{1}+b_{2}\right)>0
$$

Hence the solution set is optimal, i.e., $\left(p_{1}^{*}, p_{2}^{*}\right)$ and $T P$ is strictly concave functions.

\section{Numerical results and discussions}

In this section, three numerical analysis has been conducted to analyze both before pandemic supply chain system and the during pandemic supply chain recovery model. Numerical 1 suggests the optimality decision in the before the pandemic, numerical 2 implies the optimal strategy under in the same channel during the pandemic situation without recovery strategy, and numerical 3 decides an optimal decision with recovery channel during the pandemic. Some of the key parameter values are taken from Barman et al. (2020) and Maihami and Kamalabadi (2012) and some parameters are taken hypothetically. We also analyzed the optimal profit when the manufacturing firm does not take any step for recovery, known as a no-action situation.

\subsection{Results of profit function in before pandemic situation}

Numerical $1 \mathrm{We}$ assume that the following data to determine the profit of supply chain system before pandemic; $P=600, a=500, b=6.6, M=\$ 20, h=\$ 5, O=\$ 100$.
Selling price of a product in normal situation before pandemic is calculated by using Eq. (3) that is $p^{*}=\$ 48.62$. Also the total supply chain profit calculated from Eq. (1) is $T P^{*}=\$ 4892.40$.

\subsection{Results of profit function during pandemic under no recovery plan}

Numerical 2 During a pandemic, if a manufacturing firm does not take any action to recover the customer demand which decreases simultaneously due to lower market potential, then the supply chain profit will be reduced and it is analyzed in following. For this, we assume the market potential is reduced, $a=420$ during pandemic for no-action taken by the manufacturer and the other parameters value are same as previous example (as numerical 1), i.e., $P=600, b=6.6$, $M=\$ 20, h=\$ 5, O=\$ 100$.

Therefore, Eq. (3) gives the optimal sales price $p^{*}=\$ 42.40$ and Eq. (1) total profit of the supply chain will be $T P^{*}=\$ 2957.73$.

\subsection{Results of profit function during pandemic under the recovery plan}

Numerical 3 To analyze the result for the recovery model, we have considered the following data in which some data are hypothetical and some data taken from other papers. We assume the market potential is unchanged in the recovery plan and the same as the previous situation (Numerical 1). But this market potential (Numerical 1) splits between two delivery channel as $a_{1}=200$ and $a_{2}=300$. Also some extra cost parameters assume hypothetically as $f=\$ 1.0$, $v_{1}=\$ 1.5, v_{2}=\$ 1.8$. The price elasticity parameter at both the channel $b_{1}=3.0, b_{2}=3.6$. Other parameters are same as previous example (Numerical 1 and Numerical 2) $P=600$, $M=\$ 20, h=\$ 5, O=\$ 100$.

For recovery model during pandemic, from Eqs. (7) and (8) individually equal to zero, we get the selling price at delivery channel 1 is $p_{1}^{*}=\$ 45.29$ and delivery channel 2 is $p_{2}^{*}=\$ 53.52$. The total profit of supply chain system during pandemic is $T P^{*}=\$ 4536.16$ from Eq. (6).

\subsection{Results and discussion}

In this section, the findings from our established model and results are discussed.

Impact of recovery strategy: The proposed strategy has a positive effect on the recovery model. A direct delivery channel strategy will prevent loss of demand during a pandemic compare to before pandemic supply chain system. Also, the sanitization of the product will help to increase the safety of the product which motivates the customer to purchase the product without any doubt from the vendor. 
Changes in the selling price: During a pandemic, if no action is taken from the manufacturer side sales price is reduced compared to normal before pandemic days. If a direct delivery channel recovery strategy is considered, the selling price is increased during a pandemic than no-action situation.

Changes in total profit: From the result of our proposed model, we can see significant improvement in profit by utilizing recovery strategy during pandemic, compared to noaction taken. Selling price play an important role in the total profit function. Figure 3 shows the concavity of the total profit $(T P)$ of before pandemic. Figure 4 shows the concavity of total profit $(T P)$ under no-action taken by supply chain system during pandemic. Figure 5 shows the concavity of total profit $(T P)$ with a recovery strategy during pandemic. Total profit increases in the recovery model during pandemic compare to the no-action situation during pandemic. But profit is always higher before the pandemic situation.

\section{Managerial insights}

The model and strategies, established in this article, can be used in deciding a recovery plan for essential items such as vegetables, bakery, and other food items during an epidemic like COVID-19. The worldwide lock-down due to COVID19 creates disruptions in the delivery of the product and drops down the market potential. The consideration of these effect of COVID-19 on the developed supply chain model, make the model more robust, practical, and realistic. This investigation provides the training by giving an implementable recovery model to deal with the effects of a pandemic like COVID-19 on the supply chain. In this study, the model is found effective in improving supply chain profit. Proper implementation of the model can help managers of the supply chains to stay feasible during the recovery procedure. Tables 2, 3, and 4 and Fig. 6a-d show the computed results

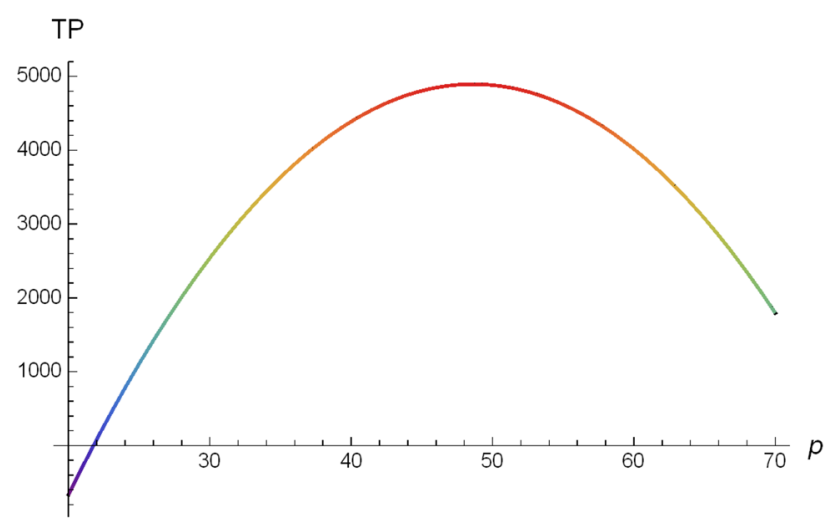

Fig. 3 Concavity of profit function $(T P)$ with respect to sales price $p$ in before the pandemic situation

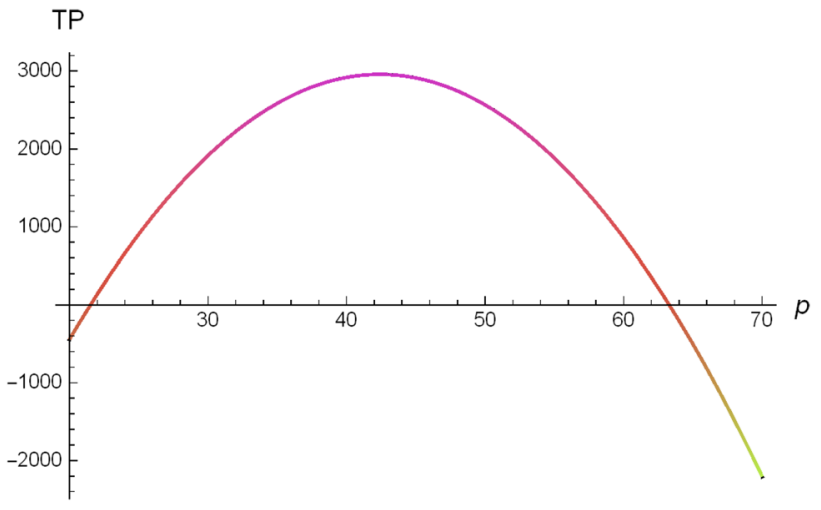

Fig. 4 Concavity of profit function $(T P)$ with respect to sales price $p$ during the pandemic under no recovery plan

by varying the value of one parameter at a time and keeping others unchanged which gives some managerial insights. We discuss the managerial insights of some main cost parameters such as manufacturing cost, holding cost, and delivery cost. Also, discuss the impact of variation of key parameters.

Impact of demand elasticity parameter $\left(a, b, a_{1}, b_{1}, a_{2}, b_{2}\right)$ : It is very difficult to estimate demand elasticity parameters in practice. So, we have shown the impact of variation of elasticity parameters on total profit and optimal solutions for the before pandemic supply chain system and no-action taken as well as with recovery strategy during pandemic in Table 2 . The total profit for the supply chain in all the situations increases with an increasing value of $\left(a, a_{1}, a_{2}\right)$. Increasing market potential implies the growth of market demand which leads to a profitable business. The manufacturing firm also bring up their sales price. The same phenomena occur for increasing price-elasticity parameters $\left(b, b_{1}, b_{2}\right)$. The observation has listed by percentage-wise changes of parameter $a, b$ or $a_{1}, b_{1}, a_{2}, b_{2}$ simultaneously.

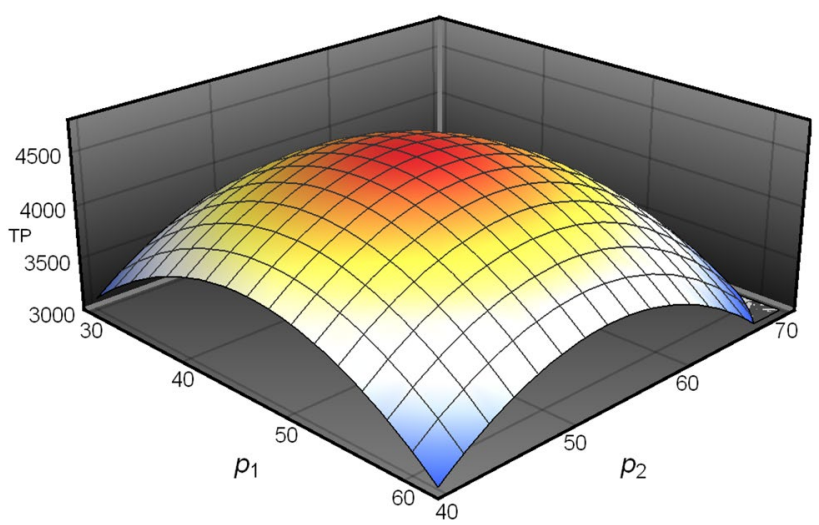

Fig. 5 Concavity of profit function $(T P)$ with respect to sales price $p$ during the pandemic under recovery plan 
Table 2 Sensitivity analysis with respect to demand elasticity parameters

\begin{tabular}{|c|c|c|c|c|c|c|c|c|c|c|c|c|c|c|c|}
\hline & \multicolumn{4}{|c|}{$\begin{array}{l}\text { Numerical } 1 \\
\text { (Before pandemic) }\end{array}$} & \multicolumn{4}{|c|}{$\begin{array}{l}\text { Numerical } 2 \\
\text { (No-action taken during pandemic) }\end{array}$} & \multicolumn{7}{|c|}{$\begin{array}{l}\text { Numerical } 3 \\
\text { (Recovery strategy during pandemic) }\end{array}$} \\
\hline & $a$ & $b$ & $p^{*}$ & $T P^{*}$ & $a$ & $b$ & $p^{*}$ & $T P *$ & $a_{1}$ & $a_{2}$ & $b_{1}$ & $b_{2}$ & $p_{1}^{*}$ & $p_{2}^{*}$ & $T P^{*}$ \\
\hline$(-20 \%)$ & 400 & 5.28 & 48.47 & 3915.42 & 336 & 5.28 & 42.28 & 2359.35 & 160 & 240 & 2.4 & 2.88 & 45.16 & 53.40 & 3628.45 \\
\hline$(-10 \%)$ & 450 & 5.94 & 48.55 & 4405.22 & 378 & 5.94 & 42.34 & 2659.34 & 180 & 270 & 2.7 & 3.24 & 45.22 & 53.46 & 4083.50 \\
\hline$(+0 \%)$ & 500 & 6.60 & 48.62 & 4892.41 & 420 & 6.60 & 42.40 & 2957.73 & 200 & 300 & 3.0 & 3.60 & 45.29 & 53.52 & 4536.16 \\
\hline$(+10 \%)$ & 550 & 7.26 & 48.69 & 5377.00 & 462 & 7.26 & 42.45 & 3254.53 & 220 & 330 & 3.3 & 3.96 & 45.36 & 53.58 & 4986.47 \\
\hline$(+20 \%)$ & 600 & 7.92 & 48.76 & 5858.95 & 504 & 7.92 & 42.51 & 2887.05 & 240 & 360 & 3.6 & 4.32 & 45.44 & 53.64 & 5434.43 \\
\hline
\end{tabular}

Table 3 Sensitivity analysis with respect to manufacturing cost $(M)$

\begin{tabular}{|c|c|c|c|c|c|c|c|c|}
\hline & & \multicolumn{2}{|c|}{$\begin{array}{l}\text { Numerical } 1 \\
\text { (Before pandemic) }\end{array}$} & \multicolumn{2}{|c|}{$\begin{array}{l}\text { Numerical } 2 \\
\text { (No-action situation dur- } \\
\text { ing pandemic) }\end{array}$} & \multicolumn{3}{|c|}{$\begin{array}{l}\text { Numerical } 3 \\
\text { (Under recovery strategy during } \\
\text { pandemic) }\end{array}$} \\
\hline & & $p^{*}$ & $T P^{*}$ & $p^{*}$ & $T P *$ & $p_{1}^{*}$ & $p_{2}^{*}$ & $T P^{*}$ \\
\hline \multirow[t]{5}{*}{$M$} & 16 & 46.67 & 5634.40 & 40.45 & 3544.01 & 43.35 & 51.58 & 5243.94 \\
\hline & 18 & 47.65 & 5256.98 & 41.42 & 3244.35 & 44.32 & 52.55 & 4883.63 \\
\hline & 20 & 48.62 & 4892.40 & 42.40 & 2957.73 & 45.29 & 53.52 & 4536.16 \\
\hline & 22 & 49.60 & 4540.68 & 43.37 & 2683.86 & 46.27 & 54.50 & 4201.54 \\
\hline & 24 & 50.57 & 4201.80 & 44.34 & 2422.84 & 47.24 & 55.47 & 3879.77 \\
\hline
\end{tabular}

Table 4 Sensitivity analysis with respect to holding cost $(h)$

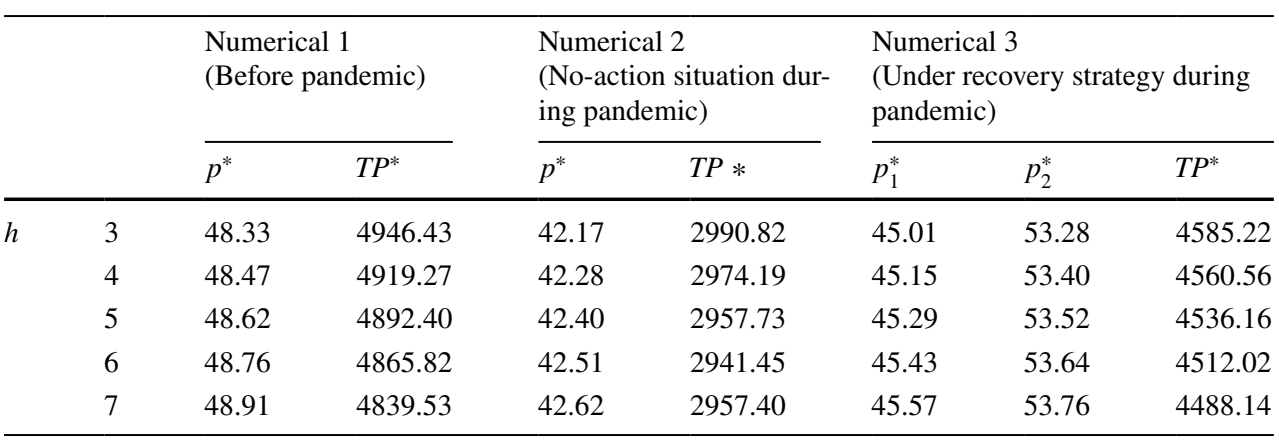

Impact of manufacturing cost: For a higher manufacturing cost, the manufacturing firm charges a higher selling price from customers to chase a higher benefit. But contrary to expectation, overall profit will decrease in all the cases shown in Table 3 and Fig. 6a.

Impact of holding cost: For increasing holding cost, selling price increases for both the before pandemic supply chain system and the during pandemic supply chain system shown in Table 4 and Fig. 6b. The manufacturing firm keeps away from stock more amount for increasing holding costs. Also firm slightly increases its selling price for the hope of gain benefit. But the total profit of the supply chain system decreases in all the cases.

Impact of delivery cost: It is an additional cost for our recovery model. Increasing delivery cost has reduced the total profit of our supply chain system. But the rate of change of total profit is less for increasing delivery cost shown in Fig. 6c and d.

\section{Conclusion}

COVID-19 is an uncommon and remarkable event that affects the supply chain around the world. The manufacturing firm faces a challenging situation due to the closedown of retail shops and restrictions on the movement of the people. These make the delivery of the product complex and could lose the demand. The COVID-19 pandemic delivered one more period in the food supply chain network and the food business. We really figure out mankind's results, economy, and food dealing. Trained professionals and specialists in the food region have various hardships ahead, e.g., 


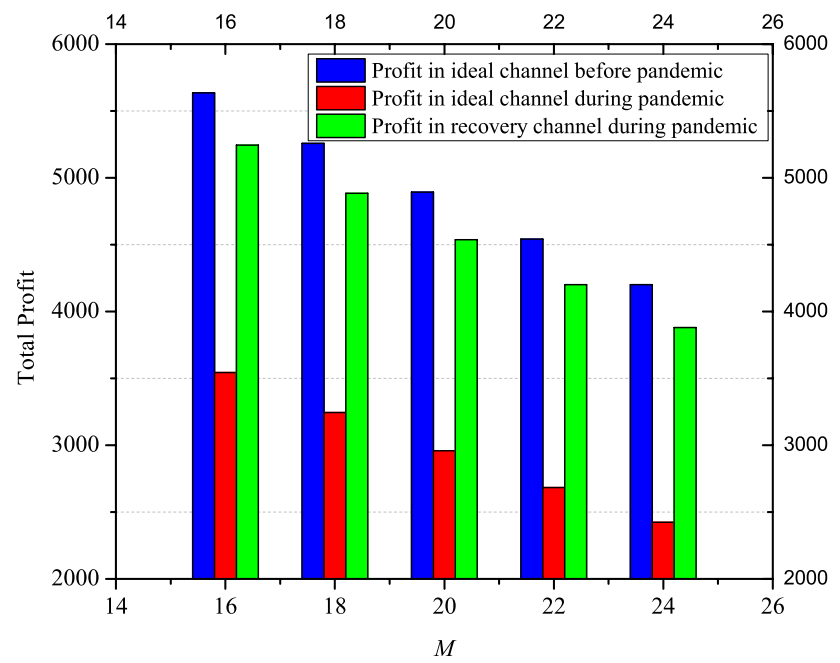

(a) $M$ vs. Total Profit $(T P)$

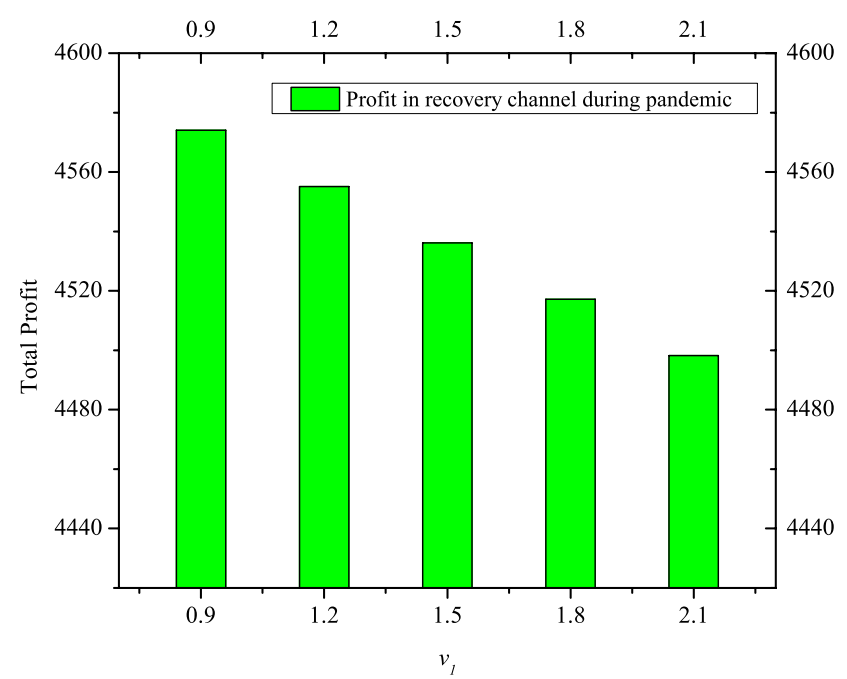

(c) $v_{1}$ vs. Total Profit $(T P)$

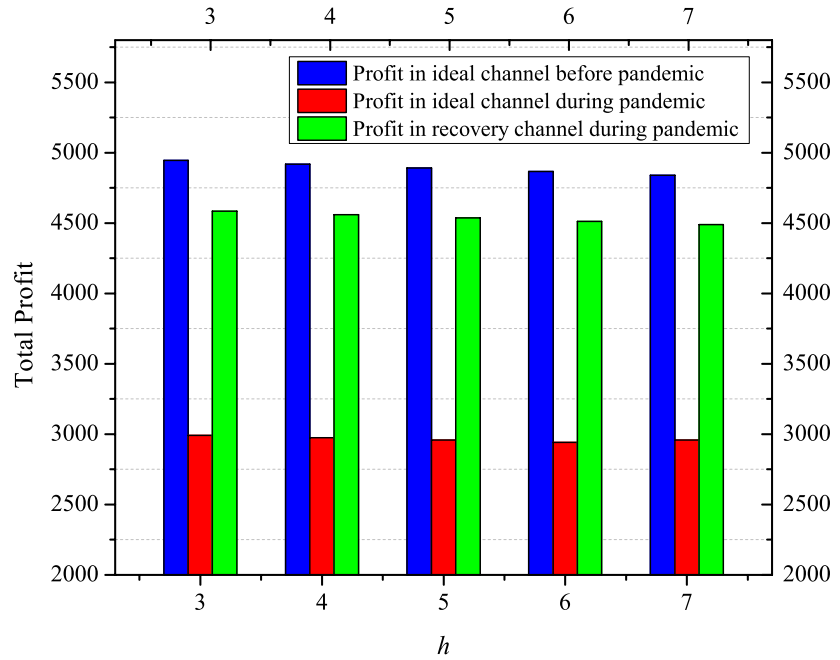

(b) $h$ vs. Total Profit $(T P)$

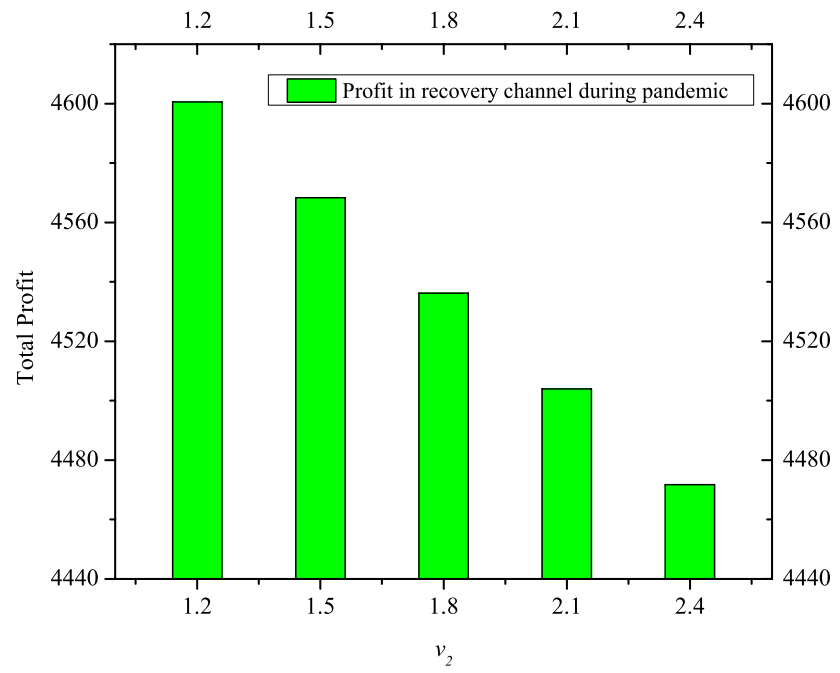

(d) $v_{2}$ vs. Total Profit $(T P)$

Fig. 6 Changes of Total Profit with respect to cost parameters

ensuring food taking care of, recognizing Covid in conditions where food is made, ready, and passed on, cleaning surfaces and working conditions adequately others. This article tackles these disruptions and establishes a food supply chain recovery model to fulfill customer demand, for a certain time in the future to maximize the total profit. In this mathematical recovery model, we consider two delivery channels by appointing some vendors as recovery strategies. Our research finds that there is a remarkable improvement in profit if manufacturing firms implement recovery strategies. This article adds the insufficient studies on developing mathematical models and techniques for recovery considering the effect of the pandemic situation.

As Covid-19 is a new experience for decision-makers of a supply chain, they would confront various difficulties to settle on recovery planning. The established model in this paper could be a base paper for supply chain decision-makers to make a recovery decision. This paper gives a mathematical model and numerical results, which could be helpful to acknowledge the effect of the COVID-19 and developed recovery strategies.

The developed recovery model is only profitable for a manufacturing firm during pandemic days which is a limitation of our model. Moreover, this paper has limitations that could be worked in future research. There are only two delivery channels in the considered recovery model, which can be extended for more number of delivery channels. In pandemic days, if the recovery strategy model is applied, profit is always better than the no-action situation of the supply chain system during the pandemic. But during normal days, before a pandemic situation, the supply chain system is always profitable. The idea can be additionally extended 
to build up a recovery strategy in a complex and worldwide supply chain network thinking about the effect of a worldwide pandemic like COVID-19. In this study, we have used some hypothetical data and some other paper's data to analyze the model. Future investigations may consider collecting real data from explicit supply chains to analyze recovery strategy. Moreover, full exact investigations, for example, indepth case studies or a huge scope review, can be conducted to give a top to bottom comprehension of how the proposed techniques help to recover the proposed methodologies and their effect on the benefit.

Acknowledgements The authors acknowledge with gratitude the valuable comments and suggestions provided by the editor and the reviewers, which enhance the overall presentation of the paper.

Funding Not applicable.

Data availability Not applicable.

\section{Declarations}

Conflict of interest The authors declare that they have no conflict of interest.

Ethical approval Not applicable.

Consent to participate Not applicable.

Consent for publication Not applicable.

\section{References}

Aday S, Aday MS (2020) Impacts of covid-19 on food supply chain. Food Qual Saf. https://doi.org/10.1093/fqsafe/fyaa024

Ali SM, Nakade K (2017) Optimal ordering policies in a multi-sourcing supply chain with supply and demand disruptions - a CVAR approach. Int J Logist Syst Manage 28(2):180-199

Alonso E, Gregory J, Field F, Kirchain R (2007) Availability and the supply chain: risks, effects, and responses. ACS Publication, Washington

Arianina K, Morris P. (2020). COVID-19 export restrictions threaten global food supply

Barman A, Das R, De PK (2021a) An analysis of optimal pricing strategy and inventory scheduling policy for a non-instantaneous deteriorating item in a two-layer supply chain. Appl Intell. https:// doi.org/10.1007/s10489-021-02646-2

Barman A, Das R, De PK (2021b) Optimal pricing and greening decision in a manufacturer retailer dual-channel supply chain. Mater Today Proc 42:870-875

Barman A, Das R, De PK (2020) Pricing and inventory policy for deteriorating item in a two-echelon supply chain: a Stackelberg duopoly game approach. In Proceedings of the 2020 8th international conference on reliability, infocom technologies and optimization (trends and future directions) (icrito) (pp 796-800)

Darom NA, Hishamuddin H, Ramli R, Nopiah ZM (2018) An inventory model of supply chain dis ruption recovery with safety stock and carbon emission consideration. J Clean Prod 197:1011-1021
Das R, Barman A, De PK (2021a) Integration of pricing and inventory decisions of deteriorating item in a decentralized supply chain: a Stackelberg-game approach. Int J Syst Assurance Eng Manage. https://doi.org/10.1007/s13198-021-01299-1

Das R, De PK, Barman A (2021b) Pricing and ordering strategies in a two-echelon supply chain under price discount policy: a Stackelberg game approach. J Manage Anal. https://doi.org/10. 1080/23270012.2021.1911697

de Sousa Jabbour ABL, Jabbour CJC, Hingley M, Vilalta-Perdomo EL, Ramsden G, Twigg D (2020) Sustainability of supply chains in the wake of the coronavirus (covid-19/sars-cov-2) pandemic: lessons and trends. Mod Supply Chain Res Appl. https://doi.org/ 10.1108/MSCRA-05-2020-0011

FAO (2020a) Adjusting business models to sustain agri-food enterprises during covid-19. FAO

FAO (2020b) Responding to the impact of the covid-19 outbreak on food value chains through efficient logistics. Available at: http:// www.fao.org/3/ca8466en/CA8466EN.pdf

Galaitsi S, Keisler JM, Trump BD, Linkov I (2021) The need to reconcile concepts that characterize systems facing threats. Risk Anal 41(1):3-15

Golan MS, Jernegan LH, Linkov I (2020) Trends and applications of resilience analytics in supply chain modeling: systematic literature review in the context of the COVID-19 pandemic. Environ Syst Decis 40:222-243

Hishamuddin H, Sarker R, Essam D (2015) A recovery model for a supply chain system with multiple suppliers subject to supply disruption. J Eng Sci Technol 10:89-101

Hosseini S, Barker K (2016) Bayesian network model for resiliencebased supplier selection. Int J Prod Econom 180:68-87

Hosseini S, Ivanov D (2020) Bayesian networks for supply chain risk, resilience and ripple effect analysis: a literature review. Expert Syst Appl 161:113649

Hosseini S, Barker K, Ramirez-Marquez JE (2016) A review of definitions and measures of system resilience. Reliab Eng Syst Saf 145:47-61

Hosseini S, Ivanov D, Dolgui A (2019) Review of quantitative methods for supply chain resilience analysis. Transport Res Part E Logist Transport Rev 125:285-307

Hosseini S, Ivanov D, Blackhurst J (2020) Conceptualization and measurement of supply chain resilience in an open-system context. IEEE Trans Eng Manage. https://doi.org/10.1109/TEM. 2020.3026465

IATA. (2020). IATA updates COVID-19 financial impacts relief measures needed. International Air Transport Association

Ivanov D, Dolgui A (2020) A digital supply chain twin for managing the disruption risks and resilience in the era of industry 4.0. Prod Plan Control. https://doi.org/10.1080/09537287.2020. 1768450]

Ivanov D, Pavlov A, Dolgui A, Pavlov D, Sokolov B (2016) Disruption-driven supply chain (re)-planning and performance impact assessment with consideration of pro-active and recovery policies. Transport Res Part E Logist Transport Rev 90:7-24

Linkov I, Carluccio S, Pritchard O, Bhreasail ÁN, Galaitsi S, Sarkis J, Keisler JM (2020) The case for value chain resilience. Manage Res Rev. https://doi.org/10.1108/mrr-08-2019-0353

Lücker F, Seifert RW, Biçer I (2019) Roles of inventory and reserve capacity in mitigating sup ply chain disruption risk. Int J Prod Res 57(4):1238-1249

Maihami R, Kamalabadi IN (2012) Joint pricing and inventory control for non-instantaneous deteriorating items with partial backlogging and time and price dependent demand. Int J Prod Econ 136(1):116-122

Ndemezo E, Ndikubwimana JB, Dukunde A (2018). Determinants of capacity utilization of food and beverage manufacturing firms in rwanda: do tax incentives matter? Available at SSRN 3217757 
Paul SK, Chowdhury P (2020) A production recovery plan in manufacturing supply chains for a high-demand item during covid19. Int J Phys Distrib Logist Manage. https://doi.org/10.1108/ IJPDLM-04-2020-0127

Paul SK, Asian S, Goh M, Torabi SA (2019) Managing sudden transportation disruptions in supply chains under delivery delay and quantity loss. Ann Oper Res 273(1-2):783-814

Pavlov A, Ivanov D, Pavlov D, Slinko A (2019a) Optimization of network redundancy and contingency planning in sustainable and resilient supply chain resource management under conditions of structural dynamics. Ann Oper Res. https://doi.org/10.1007/ s10479-019-03182-6

Pavlov A, Ivanov D, Werner F, Dolgui A, Sokolov B (2019b) Integrated detection of disruption scenarios, the ripple effect dispersal and recovery paths in supply chains. Ann Oper Res. https://doi.org/ 10.1007/s10479-019-03454-1

Pressman P, Naidu AS, Clemens R (2020) Covid-19 and food safety: risk management and future considerations. LWW

Rizou M, Galanakis IM, Aldawoud TM, Galanakis CM (2020) Safety of foods, food supply chain and environment within the covid-19 pandemic. Trends Food Sci Technol 102:293-299

Safaeian M, Fathollahi-Fard AM, Tian G, Li Z, Ke H (2019) A multi-objective supplier selection and order allocation through incremental discount in a fuzzy environment. J Intell Fuzzy Syst 37(1):1435-1455

Sebastian J. (2020). Crisis communication best practices for food safety professionals. Available at: https://www.foodqualityands afety.com/article/crisis-communication-best-practices-for-foodsafety-professionals

Shahed KS, Azeem A, Ali SM, Moktadir MA (2021) A supply chain disruption risk mitigation model to manage covid-19 pandemic risk. Environ Sci Pollut Res. https://doi.org/10.1007/ s11356-020-12289-4

Shahidi F (2020) Does covid-19 affect food safety and security? J Food Bioactives. https://doi.org/10.31665/JFB.2020.9212

Singh S, Kumar R, Panchal R, Tiwari MK (2020) Impact of covid-19 on logistics systems and disruptions in food supply chain. Int J Prod Res. https://doi.org/10.1080/00207543.2020.1792000

Trautrims A, Schleper MC, Cakir MS, Gold S (2020) Survival at the expense of the weakest? man aging modern slavery risks in supply chains during covid-19. J Risk Res. https://doi.org/10.1080/13669 877.2020 .1772347

Trump BD, Linkov I (2020) Risk and resilience in the time of the COVID-19 crisis. Springer, New York

UNTWO (2020) 